\title{
Knowledge space oddity: How to increase the intensity and relevance of the technological progress of European regions
}

\author{
Roberta Apa ${ }^{\mathrm{a}}$, Ivan De Noni ${ }^{\mathrm{b}}$, Luigi Orsi ${ }^{\mathrm{c}}$, Silvia Rita Sedita ${ }^{\mathrm{d}, *}$ \\ ${ }^{a}$ University of Bergamo, Department of Management, Economics, Quantitative Methods, Italy \\ ${ }^{\mathrm{b}}$ University of Brescia, Department of Economics and Management, Italy \\ c University of Milan, Department of Environmental Science and Policy, Italy \\ ${ }^{\mathrm{d}}$ University of Padova, Department of Economics and Management, Italy
}

\section{A R T I C L E I N F O}

\section{Keywords:}

Knowledge space

Technological knowledge base

Technological cumulativeness

Technological diversification

Technological relatedness

Technological progress

\begin{abstract}
A B S T R A C T
This work contributes to previous research on the relationship between specific features of a regional knowledge space and the technological progress of the region. In particular, the main element of originality of this work is to have singled out the determinants of the technological progress intensity and relevance. We acknowledge the importance of knowledge assets for new knowledge production, and we identify path-dependent processes that allow a region to become increasingly competitive in terms of innovation potential. In particular, adopting an evolutionary view of regional development, we describe the regional knowledge space through four crucial characteristics: 1) technological knowledge base, 2) technological cumulativeness, 3) technological diversification, and 4) technological relatedness. We then measure to what extent each of the knowledge space's characteristics differently affects the technological progress intensity and relevance of the region. A longitudinal study of 269 European regions over the period 1996-2012 was organized using data from REGPAT and Eurostat databases. Results show that technological relatedness affects positively both the intensity and relevance of the technological progress of European regions and that the other components of the knowledge space show a different impact on the two features of the technological progress. Finally, implications for EU policies supporting and stimulating regional technological progress are discussed.
\end{abstract}

\section{Introduction}

Over the last ten years, the role of knowledge in fostering regional development and technological progress has been of particular interest for European policy makers, as well being expressed in the Lisbon Agenda in 2005, and in the most recent Europe 2020 strategy, where actions are planned to "improve the conditions for innovation, research and development" (EUCO, 2010). The objective is to sustain in Europe a dynamic knowledge-based economy, based on the production and use of advanced technologies (European Commission (EC), 2010).

From a theoretical point of view, many authors have applied the endogenous growth theory to the understanding of the drivers of subnational economic development, either at the city or the regional level (Cheshire and Magrini, 2000; MacKinnon et al., 2002; Acs and Armington, 2004; Harrison, 2006, 2007; Button et al., 2011; Stimson et al., 2011; Plummer et al., 2014). In this article we depart from studies that focus on the importance of endogenous technological progress for growth (Romer, 1990; Aghion et al., 1998), and concentrate on, among the various factors influencing technological progress, the role of regional knowledge space in shaping new knowledge production and innovation.

Literature based on an evolutionary economics approach (Dosi, 1982; Dosi et al., 1988), which underlines the main role of learning processes for understanding technological development, offers a fertile ground for further research at different levels of analysis (industry, firm, local system of production, region). The learning capacity of regions is anchored on the availability of specific regional assets for the production and dissemination of knowledge (Hudson, 1999). Since the competitive advantage of regions relies increasingly on knowledge assets and knowledge management, it is important to ask which factors provide the basis for being successful learners.

Our first research question (RQ1) is as follows: What types of preexisting knowledge are best suited to new knowledge creation in European regions? Some recent studies (Kogler et al., 2013; Tavassoli and Carbonara, 2014; Castaldi et al., 2015; Rigby, 2015; Miguelez and Moreno, 2018), grounded on evolutionary economic geography theory, have tried to investigate the features of the knowledge produced within a region that improve the chances of knowledge recombination and

\footnotetext{
* Corresponding author

E-mail addresses: roberta.apa@unibg.it (R. Apa), ivan.denoni@unibs.it (I. De Noni), luigi.orsi@unimi.it (L. Orsi), silvia.sedita@unipd.it (S.R. Sedita).
} 
new knowledge creation. In these contributions, the knowledge space is often approximated with measures of innovation input and output (such as research and development (R\&D) expenditures and patents). The main focus in the above cited literature is on the relatedness argument, disregarding other important aspects of the regional knowledge space, such as, for instance, the path dependent processes that shape the technological trajectories of regions. In this realm, it is important to underline that innovation activities have a strong cumulative nature (Feldman, 1994; Breschi, 2000). The literature on the technological regime (Malerba and Orsenigo, 1993, 1996; Lee and Lim, 2001), offers an important point of view to understand how knowledge cumulativeness could influence the generation of new knowledge, thus opening up to a new set of indicators characterising the knowledge space. Our work aims to respond to this research question from an original perspective, which considers together the more commonly used indicators of technological relatedness, with less explored indicators of the technological knowledge base and technological cumulativeness.

The second research question (RQ2) pertains to an evaluation of the output of the knowledge production process: Which are the features of the knowledge space that are able to increase the intensity of the technological progress in European regions? And are these the same, affecting the relevance of their technological progress? In the literature on regional innovation, the majority of studies have focused on innovation intensity, which is a stock measure of innovation output (Acs et al., 2002; Rigby, 2015; Paci and Usai, 2009). Recently some research works have devoted attention not only to innovation intensity, but also to the quality of the innovation output, in terms of type of innovation (radical vs. incremental - Castaldi et al., 2015) and technological impact (Jaffe and de Rassenfosse, 2017; Miguelez and Moreno, 2018) or technological importance (Benson and Magee, 2012; Nemet and Johnson, 2012). We build upon these contributions, sharing the goal of increasing the understanding of differences in the determinants of general innovation and breakthrough innovations.

By answering these research questions, this research work sheds light on the relative impact of the technological knowledge base and cumulativeness, the technological diversification and relatedness, on the capacity of regions not only to be innovative, but to be a high-quality innovator. Since existing research works on the topic adopt different units of analysis (European regions, US States, specific European countries), thus not helping to compare the empirical evidence provided, due to the variety of capitalism (Hall and Soskice, 2003) and the cultural differences (Hofstede, 1984) arguments, the definition of a unified system of indicators useful to answer the RQs is crucial.

In our work we take into consideration both measures of technological progress: innovation intensity (based on the number of patents), which is a stock measure of technological progress, and innovation relevance (based on the number of forward citations), which is a quality measure of technological progress. In more detail, the innovation relevance reflects the adoption and dissemination of innovations, mirroring the technological importance for subsequent technological developments and the economic value of innovations (Trajtenberg et al., 1997; Lanjouw and Schankerman, 2004; Hall et al., 2005; Gambardella et al., 2008; Jaffe and de Rassenfosse, 2017).

The unit of analysis is the region, and the empirical setting is Europe. Theoretically grounded in the literature of evolutionary economic geography, this study adds to the debate on the drivers of technological progress by 1) accounting for the marginal effect of the different features of a regional knowledge space, and 2) accounting for the two main features of the technological progress (intensity and relevance).

The paper proceeds as follows. In Section 2 we review the literature on regional space and technological progress, focusing on features that are more likely to encourage technological progress at the regional level, and present the research hypotheses. In Section 3 we define the methodology and provide the empirical analysis. Results are shown in Section 4. Section 5 offers some concluding remarks.

\section{Theoretical framework and hypotheses}

According to recent economic geography studies, regions are a key unit of analysis for understanding the dynamics of learning and innovation (see the debate on regional innovation system and learning region: Asheim, 1996; Cooke et al., 1997; Morgan, 1997; Braczyk et al., 1998; Hassink, 2001; Asheim and Gertler, 2005; Iammarino, 2005).

The competitiveness of regions is based on innovation and on the capacity to understand, explore and exploit knowledge assets conducive to continuous technological progress. In this context, we are moving increasingly towards a knowledge-based economy in which knowledge is fundamental to enhancing productivity and economic value (Castells, 1996; Cooke, 2002) at regional and national levels. With this in mind, it is important to understand how the accumulation of knowledge in a region can influence its capacity to produce new knowledge and thus lead to technological progress. Studies that focus on the role of knowledge in economic systems consider knowledge to be the most important strategic resource and learning the most important process (Lundvall and Johnson, 1994). In particular, Lundvall and Johnson (1994) argue that know-how has become the key resource for firms in order to stay abreast of product and process innovation. Alongside this perspective, the literature on innovation highlights that the invention process is path-dependent, since the inventions that come before influence those coming after (Jaffe and de Rassenfosse, 2017) and pays attention to the role of previous knowledge in leveraging incremental (Bierly and Chakrabarti, 1996; De Carolis and Deeds, 1999) and radical innovation (Hill and Rothaermel, 2003; Miller et al., 2007; Zhou and Li, 2012).

Nevertheless, not all types of pre-existing knowledge are equally distributed and successfully combined to contribute to technological progress; therefore, the aim of this paper is to investigate how different characteristics of the regional knowledge space (technological knowledge base, technological cumulativeness, technological diversification, and technological relatedness) could impact on the technological progress in terms of innovation intensity and relevance.

\subsection{Technological knowledge base and technological progress}

The accumulation of technological knowledge creates increasing returns in scale in many contexts (Grossman and Helpman, 1991); thus, a region with a consistent base of technological knowledge has a better chance of activating learning processes that will increase the capacity to produce new technological knowledge than regions without a consistent base (Arthur, 1996). Moreover, technological innovation is commonly understood to be a cumulative process in which most new artefacts are being invented by recombining existing technologies in a new manner (Arthur, 2007; Tria et al., 2014; Castaldi et al., 2015). Consequently, the stock of knowledge accumulated in a region increases its future invention/innovation capacity. It follows that the size of the knowledge base is related to the region's technological change (Ahuja and Katila, 2001; Fleming, 2001). Smith et al. (2005) point out that existing knowledge influences the extent to which new knowledge is created, and new knowledge that is created in turn becomes part of the knowledge stock. A dynamic and self-reinforcing system of knowledge production is in place. The accumulation of knowledge leads to improved performance in terms of technological progress, giving rise to a sort of Matthew effect, in which "the rich get richer" (Merton, 1988); i.e., regions with a larger knowledge base are more likely than those with a smaller knowledge base to produce new knowledge and to maintain their status of being rich in knowledge assets. A higher innovation potential is typically joined by a larger organizational and institutional thickness of the regional innovation system, able to provide better infrastructures and research support for knowledge transfer, knowledge spillovers and innovation processes (Asheim et al., 2011). This leads to the articulation of our first baseline hypothesis. 
Hypothesis 1a. The size of the technological knowledge base positively affects the intensity of the technological progress of regions.

The relationship between the size of the technological knowledge base and the regional innovation relevance is not clearly defined in the literature. Some authors highlighted the absence of a significant impact of the technological knowledge base on innovation relevance. In more detail, when analysing the relationship between level of R\&D at the firm level and quality of patents from panel data on manufacturing firms in the US for the period 1980-93, Lanjouw and Schankerman (2004) did not find any significant correlation, thus, suggesting that the magnitude of the innovative effort does not have any impact on the relevance of the technological progress of a region. Nevertheless, following a process of technological exhaustion, which could undermine the ability to reach for radically new technologies, it is likely to observe a negative impact of the size of the technological knowledge base on the relevance of the innovative output (Fleming, 2001). The assumption of bounded rationality and local search (March, 1991) explains the tendency of inventors to recombine knowledge within a familiar set of technology components, or refine previous combinations, thus locking in the innovation process within an innovation pattern that is more oriented to the exploitation of local knowledge spaces rather than the exploration of distant knowledge spaces. Accordingly, inventive certainty is preferred to inventive uncertainty (Fleming, 2001), favouring a technological exhaustion process, where most of the possible relationships between a set of components have already been tried. These arguments lead to the formulation of our Hypothesis $1 \mathrm{~b}$ :

Hypothesis $1 \mathrm{~b}$. The size of the technological knowledge base negatively affects the relevance of the technological progress of regions.

\subsection{Technological cumulativeness and technological progress}

The generation of technological progress is linked to a region's ability to explore, select and use existing knowledge. This ability is a specific feature of the regional technological regime (Malerba and Orsenigo, 1996), and is widely addressed by evolutionary literature as cumulativeness. The cumulativeness of technological advances is the degree to which new technology builds on existing technology (Nelson and Winter, 1982). Technological cumulativeness is related to the fact that one innovation can generate a stream of subsequent innovations that improves upon the original or creates new knowledge that is used for other innovations in related areas (Malerba and Orsenigo, 1993; Breschi, 2000; Breschi et al., 2000; Peneder, 2010; Lee et al., 2017). The process of knowledge selection and the recombination of existing knowledge into new knowledge, become relevant steps in shaping the region's potential for technological progress. Accordingly, the analysis of the knowledge sources used by the region is essential to determine the relative adoption of different technologies over time and influences the path of technological progress generated by any given invention (Banerjee and Cole, 2010). Following a pre-existing trajectory could be easier, less expensive and resource saving, because of the use of capabilities that already exist and are well managed in the region. Therefore, the selection and recombination of a higher number of knowledge sources allows a wider knowledge pool, where each component can be recombined to create new knowledge and might lead to technological progress, especially in terms of innovation intensity. Building on the Schumpeterian tradition, and aligning with Malerba and Orsenigo (1996); Breschi et al. (2000), and Lee and Lim (2001), we consider two main patterns of innovations: a creative destruction pattern, in which innovations are less related to previous innovations, and a creative accumulation pattern where innovations are highly related to previous innovations and could be interpreted as result of an exploitation process of pre-existing technologies. In particular, our Hypothesis 2a refers to technological trajectories of regions dominated by Schumpeter Mark II technologies (Schumpeter, 1942), traditionally developed by scale intensive firms (Pavitt, 1984) within routinized innovation regimes and a high concentration of innovative activities, especially related to the exploitation of existing technologies (Breschi et al., 2000; Peneder, 2010; Frenz and Prevezer, 2012; Lee et al., 2017). In this context, the process of technological accumulation leads to augment the intensity of the technological progress.

Hypothesis 2a. Technological cumulativeness positively affects the intensity of the technological progress of regions.

In addition, the identification and measurement of which knowledge sources are recombined to create new knowledge can help to assess the degree of novelty of new inventions and may be informative of the intrinsic dynamics of the technological process. Trajtenberg et al. (1997) highlighted that more trivial inventions are more extensively rooted in what has gone before, while more basic inventions are less incremental in nature and thus have fewer identifiable antecedents. Therefore, the size of the portfolio of knowledge sources, to which a patent refers, may signal that the innovation is more incremental in nature (Lanjouw and Schankerman, 2004) and also mirrors the existence of a regional innovation strategy aimed at following the inventive trajectory to which it is tied (Jaffe and de Rassenfosse, 2017).

Taking into consideration the regions dominated by Schumpeter Mark I technologies (Schumpeter, 1934), characterised by creative firms that operate within a regime of low technological cumulativeness and by innovations that continuously disrupt the existing technological routines (Breschi et al., 2000; Peneder, 2010; Frenz and Prevezer, 2012; Lee et al., 2017), we expect that, in this context, regions might be able to produce more impactful and relevant innovations. Our Hypothesis $2 \mathrm{~b}$ thus follows.

Hypothesis 2b. Technological cumulativeness negatively affects the relevance of the technological progress of regions.

\subsection{Technological diversification and technological progress}

Knowledge that is not oriented to new directions could lead to closure and increase the risk of lock-in into a specific technological domain, allowing only the exploitation of existing knowledge. The exploration of new knowledge in different technological domains may open up new opportunities and expand the technological possibilities (Boschma and Lambooy, 1999; Martin and Sunley, 2006, 2010; Rosenzweig, 2017). Therefore, new knowledge is created predominantly by processes of recombination of knowledge from different technological classes, which represent different knowledge sources. These types of knowledge sources tend to be specific forms of scientific and applied knowledge related to technology, markets and organizational aspects (Grillitsch et al., 2015). Regions accumulate know-how across a variety of disciplines and heterogeneous market domains through extensive processes of knowledge exploration (Prabhu et al., 2005). Processes of new knowledge creation and innovation in a region are influenced not only by the size of the technological knowledge base, but also, and maybe more importantly, by the diversification of this knowledge base (Audretsch and Vivarelli, 1996; Saviotti, 1996; Rodan and Galunic, 2004; Frenken et al., 2007; Tavassoli and Carbonara, 2014). The exposure to heterogeneous knowledge allows for new recombination opportunities and spillovers, which sustain the creativity of firms in the region, leveraging on their opportunity recognition and recombinant abilities, and boosting their capacity to develop new knowledge and innovation (Kogut and Zander, 1992; Rodan and Galunic, 2004). A diversified knowledge base is more likely to be conducive to novelties and expands regional learning capabilities, avoiding lock-in and path-dependent processes, which are particularly critical in case of external economic shocks (Sedita et al., 2017). Some studies have shown that regional knowledge heterogeneity influences positively both knowledge creation and innovation performance (Jacobs, 1969; Phene et al., 2006), providing opportunities for novel 
linkages and associations. The diversification of knowledge augments the selection opportunities and decreases the likelihood of technological dead-ends (Singh and Fleming, 2010). Following this line of reasoning, a region that recombines broader pre-existing knowledge could be more inclined to create new knowledge and actively contribute to technological progress, in terms of innovation intensity, than a specialized region.

Hypothesis 3a. Technological diversification positively affects the intensity of the technological progress of regions.

Moreover, the recombination of widely diversified knowledge is likely to lead to impactful innovation (Benson and Magee, 2012; Nemet and Johnson, 2012), with high economic value (Fleming and Sorenson, 2004; Kaplan and Vakili, 2015), which can lead to completely new operational principles, functionalities and applications (Fleming, 2001; Saviotti and Frenken, 2008; Castaldi et al., 2015). The combination of diverse technological components generates unique and thus genuine innovation (Van de Vrande, 2013) that could enable further combinations (Nemet and Johnson, 2012). A diversified knowledge base allows the combination of ideas that had not been brought together before, thus leading to increased innovation performance (Ahuja and Lampert, 2001; Singh and Fleming, 2010; Rosenzweig, 2017). In this perspective, we hypothesize a positive relationship between technological diversification and the relevance of the technological progress.

Hypothesis 3b. Technological diversification positively affects the relevance of the technological progress of regions.

\subsection{Technological relatedness and technological progress}

Despite the role of the diversified knowledge base in fostering technological progress being well recognised in the literature, we have to take into consideration that high diversification is often accompanied by high risks and switching costs, because of the limited capabilities of firms and the peculiarities of their business models, which clearly hinder their possibilities to move their technological frontier into completely different knowledge domains (Boschma et al., 2014). The recombination of diversified knowledge sources requires strong abilities to: firstly recognise the value of distant knowledge, secondly assimilate it, and thirdly exploit it for technological and commercial ends (Cohen and Levinthal, 1990).

Fornahl et al. (2011), stemming from the concept of cognitive proximity of Nooteboom (2000), introduced the definition of an "optimal cognitive distance", which characterizes knowledge that is neither identical (hence it can be usefully exchanged) nor too distant (therefore it can still be effectively absorbed), but related. Relatedness can therefore be associated with knowledge transfers that occur across industries because of their optimal cognitive distance. Some degree of cognitive proximity is desirable because it ensures effective communication and common understanding, while guaranteeing the avoidance of cognitive lock-in.

As for the industrial structure, Frenken et al. (2007) introduced the concept of related and unrelated variety, highlighting that regional variety impacts on regional development only if regional sectors are technologically related to each other. Other authors have applied these concepts to different regional contexts: The Netherlands (Frenken et al., 2007), Italy (Boschma and Iammarino, 2009; Quatraro, 2010), Sweden (Boschma et al., 2009), Great Britain (Bishop and Gripaios, 2010), Germany (Brachert et al., 2011), Spain (Boschma et al., 2012), Finland (Hartog et al., 2012), European Regions (Cortinovis and Van Oort, 2015), confirming that related variety tends to contribute positively to regional growth in terms of employment or productivity.

Shifting from the analysis of the features of the regional industrial structure to the determinants of the regional growth and development, the concept of relatedness is applied to the technological trajectories of the innovation process. Technological relatedness at a regional level measures how regions' diversification possibilities are affected by the degree to which technologies are connected to one another, where the link between two technologies is usually measured by how much they share in terms of common scientific knowledge, technical principles, heuristics, and common needs in general (Petralia et al., 2017). Several studies have confirmed the role of relatedness in fostering technological or industrial development - through "branching processes". Regarding the industrial diversification of regions, Neffke et al. (2011) and Essletzbichler (2015) highlighted that regions are more likely to enter into industries that are related to those already existing. Similarly, Kogler et al. (2013), Boschma et al. (2015) and Rigby (2015), focusing on regional technological diversification, found that technologies related to pre-existing technologies in U.S. cities or metropolitan regions increase the possibility of entering those regions and that they are crucial for technological change. Quatraro and Usai (2017) found that as the trajectory becomes more familiar, innovating agents learn to move across the knowledge space and are more likely to undertake organized searches directed towards the combination of technologies that are close to one another. Therefore, if the knowledge space of a region is characterized by a patenting activity alongside a large number of related technological classes, the region is more likely to host regional knowledge spillovers between these related technological classes, which provide venues for new knowledge creation.

Following this line, a region that recombines related pre-existing knowledge could be more inclined to create new knowledge, and actively contribute to technological progress. In this direction, the potential of technological relatedness is widely stressed by regional innovation literature (Boschma et al., 2015; Frenken et al., 2007) and it currently represents a critical point in the diffusion of smart specialization policies. However, very little systematic evidence exists. Specifically, Tavassoli and Carbonara (2014) proved that technologically related variety affects positively the patent intensity of Swedish regions. Miguelez and Moreno (2018) confirm this relationship for European regions. In addition, their study points out that the quality and relevance of innovations may benefit from both related and unrelated variety. Differently, Castaldi et al. (2015), focusing on US cases, claim that technologically related variety increases innovation performance in terms of intensity, but they found a positive, although not significant, effect of related variety on breakthrough innovation, which mostly relies on unrelated variety. In this light, technological relatedness is typically expected to influence innovation intensity while the effect on innovation quality is not so widely shared, even though it seems more inclined to be positive, especially with reference to the European context.

Hypothesis 4a. Technological relatedness positively affects the intensity of the technological progress of regions.

Hypothesis $4 \mathrm{~b}$. Technological relatedness positively affects the relevance of the technological progress of regions.

\section{Methodology}

This study investigates the relationship between regional knowledge space and technological progress by exploring the relative impact of the technological knowledge base, technological cumulativeness, technological diversification and technological relatedness of the regional knowledge space. The sample involves $\mathrm{N}=269$ regions in 29 countries (European Union plus Norway). NUTS2 (Nomenclature of Territorial Units for Statistics) is used to define the regional level. Data concerning patents, patent citations, technological classes and inventors were collected from the Organisation for Economic Co-operation and Development (OECD) REGPAT database (version released 02/2016). Patent data have been regionalized on the basis of the inventors' address. Fractional counting is applied in case of multiple inventors per patent coming from different regions (De Noni et al., 2017). 
Technological classification refers to International Patent Classification (IPC) classes at the 4-digit level. The final panel dataset covers the time period from 1996 to 2012. Explanatory variables (x) about regional knowledge features are measured on the previous five-year moving average in order to mitigate the effect of time fluctuations. Differently, the dependent variables (y) are computed on the following three-year moving time-windows, lagged one period with respect to the explanatory variables. The time lags are introduced to minimize endogeneity and reverse causality issues. To sum up, if y is operationalized gathering data from $\mathrm{t}$ to $\mathrm{t}+2, \mathrm{x}$ is defined from $\mathrm{t}-1$ to $\mathrm{t}-5$. In addition, the control variables, which concern the economic and demographic regional features and are provided by the statistical office of the European Union (Eurostat), are measured in t-1. Therefore, because of these variables' structure, the number of time series in the panel dataset is limited to $T=9$. $^{1}$

Finally, spatial modelling with individual fixed effects is implemented to control for potential spatial dependence of innovation and for a number of unobserved factors at the regional level, such as institutional setting or policy differences (Cortinovis et al., 2017).

\subsection{Variables}

In this study, we define technological progress by looking at its intensity and relevance at the regional level. Explanatory variables involve data on technological knowledge base, technological cumulativeness, diversification and relatedness. Finally, we introduce R\&D capacity, human capital, manufacturing specialization and population density as controls.

\subsubsection{Dependent variables}

Technological progress intensity. Despite the limitations ${ }^{2}$ for measuring technological knowledge (Alcacer and Gittelman, 2006; Lane et al., 2006) through patents, nevertheless they have been found to be a good proxy for computing innovation performance at a regional level (Acs et al., 2002) and are widely used today. In addition, since patents refer to the output of a lagged invention process (Paci and Usai, 2009; Crescenzi et al., 2012), using a lag window larger than three years is typically recommended (Marrocu et al., 2013; Paci et al., 2014). To sum up, technological progress intensity is here measured as the logarithmic transformation of the cumulated regional patent contribution per million inhabitants over a shifted three-year window ${ }^{3}$; the higher the index, the higher the regional capacity to innovate.

Technological progress relevance. This study uses the citations a given patent produces (forward citations) as an indicator of its technological impact and economic value (Jaffe and de Rassenfosse, 2017). The forward citations that refer to the technological descendants of an invention and its extent suggest the technological importance of a patent for the development of subsequent technologies (Harhoff et al., 2003; Hall et al., 2005; Nemet and Johnson, 2012). The number of forward citations in the following five years from application is automatically provided per patent by the OECD REGPAT database. Then, we computed the logarithm of the average number of forward citations associated with the cumulated regional patent contribution over three-year moving time-windows ${ }^{4}$. The more a patent is cited by future patents, the greater the likelihood of being adopted for exploiting a

\footnotetext{
${ }^{1}$ We also tested five-year moving time-windows of dependent variables. However, since this procedure further decreases the time span of the panel dataset from $T=9$ to $T=7$ and does not change the findings significantly, we moved the models concerning the five-year lagged dependent variables in Appendix A.

${ }^{2}$ Although patent data are typically used to measure knowledge outputs and innovation, they do not represent the overall knowledge production of a region (Rigby, 2015)

${ }^{3}$ To check the robustness of our results, we operationalized also a 5-year time window instead of a 3-year time window for our dependent variable (see Appendix A).

${ }^{4} \mathrm{Also}$, in this case we operationalized an additional 5-year time window instead of a 3year time window (see Appendix A).
}

technological trajectory and the higher the estimation of its potential relevance. On the basis of the findings of Hall et al. (2005), the measure also includes self-citations, which are as valuable as citations from external patents.

\subsubsection{Independent variables}

Technological knowledge base. The size of the technological knowledge base of a region represents the regional capacity to produce and accumulate knowledge stock, which may potentially be exploited to create technological progress. Based on Dettori et al. (2012), this index is operationalized as the logarithmic transformation of the cumulative patent stock of the region in the previous five years over the total population. The larger the knowledge stock of a region, the higher the recombination potential and expected innovation performance. The use of this variable for estimating the regional technological progress intensity corresponds to running a dynamic panel model.

Technological cumulativeness. Backward citations inform about the technological antecedents of an invention. The basic idea is that the extent to which inventions rely on antecedents proxies the degree of path-dependency between new and pre-existing knowledge, indicating their novelty or radicalness (Jaffe and de Rassenfosse, 2017). Thus, technological cumulativeness is operationalized as the logarithm of the average number of regional backward citations (within or outside the region) reported by patents filed by the region over five-year moving time-windows.

Technological diversification. Technological diversification of a region is supposed to be strongly related to the extent of knowledge sources that inventors belonging to a region can acquire, exploit and transform into new knowledge (Zahra and George, 2002). Thus, it is not just a matter of a diversified structure of internal knowledge base, but mainly of a regional capacity for accessing and using diversified knowledge in the invention process; however, since absorptive capacity strongly depends on cognitive proximity (Noteboom, 2000), the diversity of the regional knowledge base can have a positive impact on the heterogeneity of the regional knowledge sources. In other words, the more diversified the knowledge of a region, the higher the opportunity for that region to have access to and use differentiated knowledge sources. In order to measure this type of technological diversification, we refer to backward citations rather than patents and specifically apply the Patent Originality Index, provided by OECD REGPAT, which refers to the breadth of the technology fields on which backward citations of a patent rely (Jaffe and de Rassenfosse, 2017). Based on Hall et al. (2001), the originality index measures the degree of heterogeneity of the backward citations across patent classes (IPC4level). The higher the index, the larger the number of diverse knowledge sources a patent is based upon, and therefore the higher the probability to obtain original results; conversely, the lower the value, the higher the concentration of the citations within fewer technological fields, and therefore the higher the probability that the patent mirrors an incremental innovation. An average value is calculated at the regional level on the patent stock of a region over five-year moving timewindows.

Technological relatedness. Following Balland et al. (2015), we firstly construct matrices of the technology space in order to measure the degree of relatedness across 438 IPC4-level technological classes by computing a technology-technology matrix based on normalized cooccurrences of technological classes ${ }^{5}$ within the same patent over fiveyear moving time-windows. Second, we compute incidence regionstechnologies matrices based on the relative distribution of regional patents over five-year moving time-windows. A dichotomized matrix of

\footnotetext{
${ }^{5}$ Differently from United States Patent and Trademark Office (USPTO) patents, European Patent Office (EPO) patents are not required to identify a priority technological class. Thus, most of them declare multiple technological classes. Technological space defines how often two technologies are found within the same patent. In other words, two technological classes co-occur if they are both cited in the same patent.
} 
Revealed Comparative Advantage (RCA) is further defined by considering the technologies with a location quotient ${ }^{6}$ higher than 1 . Finally, the average relatedness density within the regional patent portfolio is computed by integrating the IPC technological space matrix and RCA matrix (Balland, 2017); the higher the value, the higher the relatedness across the most relevant patent technologies of a region.

\subsubsection{Control variables}

$R \& D$ expenditures. Gross domestic expenditure on $R \& D$ as a percentage of gross domestic product is an indicator of high political importance at the EU, national, and regional levels. R\&D intensity is expected to have a positive impact on innovation, assuming that there exists a positive correlation between technological input and output (Gilsing et al., 2008).

Human capital. Since the attitude of a region to innovate depends on the average level of human capital within the local economy (Lee et al., 2010), tertiary educational attainment is used as a proxy for human capital; the higher the educational level, the higher the potential number of inventors. This indicator, provided by Eurostat, is specifically based on the EU Labour Force Survey. It is defined as the percentage of the population aged 25-64 who have successfully completed tertiary studies (e.g. university, higher technical institution, etc.). Educational attainment is defined with reference to the International Standard Classification of Education 1997 levels 5-6 for data up to 2013.

Manufacturing specialization. Since sectors have different technology and innovation opportunities, and manufacturing is typically more inclined to innovate than services (Hipp and Grupp, 2005) - especially when innovation is measured in terms of patents - manufacturing specialization is used as the control. Specifically, the level of manufacturing concentration is measured as the share of employees operating within the manufacturing industry with respect to the total number of employees in a given region.

Population density. Population density (population divided by land area in square kilometres) is usually applied as a proxy for externalities related to the urbanization process (Mameli et al., 2012). Urbanization is positively associated with the presence of universities, industry research laboratories, trade associations and other knowledge-generating organizations (Frenken et al., 2007). Thus, urban economies may better support regional innovation performance than non-urban economies.

\subsection{Model estimation}

In this study, we use a spatially lagged model based on a 9-panels dataset, since the ordinary least squares (OLS) estimates, though unbiased, are inefficient when spatial dependence is present (Anselin, 1988). Spatial lag is suggestive of a possible diffusion process of knowledge creation because of the spatial dimension of social interactions and collaboration processes, which are typically considered as important drivers of innovation and knowledge spillovers. Moreover, fixed effects are typically preferred to random effects in modelling regions because of the distribution of innovation, which is inclined to be influenced by observed and latent time-invariant territorial features. Finally, we introduce individual effects (regional effects in our case) in order to analyse changes at the individual level and control for regional heterogeneity. The use of $n$-year moving time-windows mitigates the effect of time fluctuations and makes it unnecessary to control for time effects.

In addition, a number of statistical tests are applied to verify our choices. Firstly, the F-test is performed by using the pFtest function of $\mathrm{R}^{7}$ 's plm package, and confirms that both fixed and random effects models better fit than OLS. Secondly, the Moran I test is applied to

\footnotetext{
${ }^{6}$ The location quotient is applied by comparing the share of each technology in a given region to the share of this technology in overall sampled European countries.

${ }^{7} \mathrm{R}$ is an open source software environment for statistical computing and graphics.
}

measure the spatial autocorrelation, given a set of features and an associated attribute. The result confirms that regional technological progress is a spatially clustered process. Furthermore, Lagrange Multiplier (LM) and Robust Lagrange Multiplier (RLM) tests confirm that regional technological progress is spatially lagged. Finally, the Hausman test statistically confirms that fixed effect is more consistent than random effect modelling (Greene, 2008). The results of the tests are reported in Table 3 and Appendix A. Moreover, fixed effect models are the safest choice to eliminate possible omitted variables bias, such as cultural and social aspects (Nickell, 1981). Important differences between regions are the consequences of region-specific effects related to regional systems of innovation and to specific histories of firms and industries across regions.

We used the R package splm (spatial panel linear model) to estimate the regressive models with a maximum likelihood approach controlling for spatial lag dependence.

Thus, following Anselin (1988), we defined the expression of the spatial fixed effects lag model as:

$Y=\lambda W y+X \beta+\varepsilon$

where $Y$ is a vector of the dependent variables, $X$ is a matrix of the explanatory and control variables, $\beta$ represents the vector of the coefficients, $\varepsilon$ is the vector of the residuals, and $W$ is the spatial weight matrix, showing the strength of the interaction between two regions.

\section{Results}

Tables 1 and 2 present the descriptive statistics and the correlation matrix for all variables. As Table 2 shows, all the explanatory variables tend to be positively correlated with the two dependent variables that measure the technological progress intensity and relevance.

The correlation values are relatively low under the cut-off point of 0.50 (O'Brien, 2007). The only exceptions are the correlations between technological knowledge base and technological relatedness, and between technological cumulativeness and technological diversification. For this reason, we entered separately all the explanatory variables in the regression models to avoid any kind of bias due to multicollinearity among explanatory regressors. Moreover, we checked for the existence of multicollinearity (see Table 3 ) by computing the variance inflation factors (VIFs) and found multicollinearity is not a problem, as the VIFs are well below the suggested cut-off value of 5 (O'Brien, 2007).

In Table 3 we present the results of the spatial panel estimations using individual effects to explain the drivers of technological progress intensity (Models 1a, 2a, 3a, 4a and 5a) and technological progress relevance (Models 1b, 2b, 3b, 4b and 5b) in European regions.

As a baseline model (see Models $1 \mathrm{a}$ and $1 \mathrm{~b}$ ) to compare our results against, we first present the outcome with only the control variables. Models 1a (tech. progress intensity) and 1b (tech. progress relevance) in Table 3 represent the effect of the control variables on the dependent variables. Models $2 \mathrm{a}$ and $2 \mathrm{~b}$ show the results of the controls after entering the technological knowledge base. Models 3a and 3b introduce the results of the controls plus the technological cumulativeness. Models 4a and 4b present the results of the controls after entering the technological diversification. Finally, Models $5 a$ and $5 b$ introduce the last explanatory variable - technological relatedness.

Generally, the overall fit of the models increases compared to the baseline in terms of lower values of generalized least square (GLS) residual variance and higher values of adjusted R squared. In other words, the introduction of the four independent terms is important in explaining the intensity and relevance of the regional technological progress, and it adds explanatory power to the models.

The analysis of the results in Table 3 on the intensity of the technological progress (see Models 1a, 2a, 3a, 4a and 5a) suggests some main considerations.

First, with respect to our research hypotheses related to the intensity of regional technological progress, we found interesting results. 
Table 1

Descriptive statistics.

\begin{tabular}{llllll}
\hline Variables & Mean & S.d. & Min. & Max. & Obs. \\
\hline Tech. progress intensity & 0.10 & 0.12 & 0.00 & 0.56 & 2421 \\
Tech. progress relevance & 0.22 & 0.10 & 0.00 & 0.64 & 2421 \\
Tech. knowledge base & 2.31 & 0.93 & 0.00 & 4.20 & 2421 \\
Tech. cumulativeness & 0.76 & 0.09 & 0.00 & 1.16 & 2421 \\
Tech. diversification & 0.63 & 0.09 & 0.00 & 0.92 & 2421 \\
Tech. relatedness & 16.83 & 10.11 & 0.00 & 42.44 & 2421 \\
R\&D expenditures & 0.01 & 0.01 & 0.01 & 0.12 & 2421 \\
Human capital & 21.76 & 8.44 & 3.70 & 48.90 & 2421 \\
Manuf. specialization & 18.32 & 6.82 & 3.70 & 36.90 & 2421 \\
Pop. Density & 344.71 & 859.69 & 3.30 & 9839.90 & 2421 \\
\hline
\end{tabular}

Model 2a shows that the intensity of technological progress is positively influenced by the size of the technological knowledge base (Model 2a, p < 0.001), fully confirming Hypothesis 1a.

Model 3a does not support Hypothesis 2a, which claims that technological cumulativeness positively affects the intensity of the technological progress of the region. Even though increments of the dimension of the knowledge sources positively affect the intensity of regional innovation performance, this result is not statistically significant (Model 3a, $\mathrm{p}>0.1$ ).

We also found not statistically significant results concerning the effect of the technological diversification of the knowledge sources. Model 4a presents a positive but not statistically significant $(\mathrm{p}<0.1)$ impact of the technological diversification on the intensity of technological progress leading us to reject Hypothesis 3a. Several studies underline that technological diversification is crucial for innovation (Harhoff and Wagner, 2009). Inventions relying on a large number of diverse knowledge sources are supposed to lead to original innovations but not to increase the intensity of the regional progress.

Technological progress intensity also depends on the technological relatedness of the knowledge space. More specifically, a region that increases (Model 5a, p < 0.01) the technological relatedness is inclined to report higher technological intensity, thus leading to confirm Hypothesis 4a.

Second, looking at the control variables (Model 1a), R\&D intensity is confirmed to have a significant and positive effect on the intensity of regional technological progress in terms of the number of fractionalized patents in all models (Marrocu et al., 2013; Castaldi et al., 2015). Human capital, even though positive across all models, is not statistically significant. Manufacturing specialization shows significant but negative effects on the intensity of technological progress. Several authors (e.g. Hipp and Grupp, 2005; Marrocu et al., 2013) suggest that regions with a large manufacturing base present better levels of patenting activities, because manufacturing is typically more inclined to innovate than other sectors. In contrast, our results show that regions with positive variations of manufacturing activities with respect to their mean value show a decrease in innovative performance, probably due to the recent crises that have strongly affected the core manufacturing regions in Europe, and accordingly they reduced their patenting activity and R\&D investment. Finally, the urbanization level measured by population density has a positive but not statistically significant impact on the intensity of technological progress. Urbanization economies seem not to confirm the benefits usually associated with the presence of universities, industry research laboratories, trade associations and other knowledge generating organizations (Frenken et al., 2007; Marrocu et al., 2013).

Third, all models confirm the importance of spatial dependence on the intensity of technological progress. The positive and significant lambda-coefficient (spatial lag dependence) means that an innovation intensive neighbourhood facilitates and promotes the technological progress of neighbouring regions (Capello, 2009; Ponds et al., 2010; Basile et al., 2012).

In Models 1b, 2b, 3b, 4b and 5b we present the results of the spatial panel estimations using individual effects to explain the drivers of the relevance of the regional technological progress.

The analysis of the results on the technological progress relevance suggests the following considerations.

With respect to our research hypotheses related to the relevance of regional technological progress, we found the following results.

Model $2 \mathrm{~b}$ presents a negative and significant $(\mathrm{p}<0.001)$ impact of the size of the knowledge base on the relevance of technological progress. This means that an increase of the regional knowledge base above the average does not lead to improvements in the relevance of technological progress. Thus, we confirm our Hypothesis $1 \mathrm{~b}$.

Model 3b suggests negative effects $(p<0.001)$ of the technological reliance on the technological progress relevance, leading us to confirm Hypothesis 2b. Probably reducing the number of regional knowledge sources leads to more original inventions or innovation with higher adoptability and diffusion potentials.

Model $4 \mathrm{~b}$ shows that a decrease in the variety and complexity of the knowledge sources inside a region can have positive and significant effects $(\mathrm{p}<0.01)$ on the relevance of inventions. Regions with lower heterogeneity in the knowledge sources are able to produce simpler technologies and this ability supports increased technological relevance. Hence, Hypothesis $3 \mathrm{~b}$ is rejected.

Technological progress relevance positively and significantly depends on the relatedness of the regional knowledge space. More precisely, a region with higher increments (Model $5 \mathrm{~b}, \mathrm{p}<0.1$ ) of relatedness in its knowledge space is inclined to produce technologies with a higher adoption rate than a region with a lower technological relatedness. This fully supports Hypothesis 4b.

Control variables present interesting results (see Model 1b). R\&D intensity is not statistically significant. Human capital shows significant but negative impacts. The innovation output of regions with higher increments of human capital seems to be of scarce relevance, thus mirroring an inefficient technology diffusion trajectory. Contrary to our expectations, human capital is negatively associated with the relevance of regional innovations; however, there is a rational explanation. This counterintuitive result depends on the operationalization of the human

Table 2

Correlation matrix.

\begin{tabular}{|c|c|c|c|c|c|c|c|c|c|c|c|}
\hline & Variables & 1 & 2 & 3 & 4 & 5 & 6 & 7 & 8 & 9 & 10 \\
\hline 2 & Tech. progress relevance & $0.34^{* * * *}$ & 1 & & & & & & & & \\
\hline 3 & Tech. knowledge base & $0.75^{* * *}$ & $0.17^{* * * *}$ & 1 & & & & & & & \\
\hline 5 & Tech. diversification & $0.18^{* * * *}$ & $0.18^{* * * *}$ & $0.11^{* * *}$ & $0.51^{* * *}$ & 1 & & & & & \\
\hline 6 & Tech. relatedness & $0.63^{* * *}$ & $0.37^{* * *}$ & $0.55^{* * *}$ & $0.18^{* * *}$ & $0.26^{* * *}$ & 1 & & & & \\
\hline 7 & R\&D expenditures & $0.66^{* * *}$ & $0.34 * * * *$ & $0.48^{* * *}$ & $0.12^{* * *}$ & $0.24^{* * *}$ & $0.49^{* * *}$ & 1 & & & \\
\hline 8 & Human capital & $0.39^{* * * *}$ & $0.29 * * *$ & $0.25^{* * *}$ & $0.23^{* * *}$ & $0.28^{* * * *}$ & $0.41^{* * *}$ & $0.51^{* * *}$ & 1 & & \\
\hline
\end{tabular}

Notes: Significance levels are ${ }^{* * *} \mathrm{p}<0.001,{ }^{* *} \mathrm{p}<0.01,{ }^{*} \mathrm{p}<0.10$. 
capital variable (the percentage of the population aged 25-64 who have successfully completed tertiary studies) and the econometric model specification used. Fixed effects models with individual effects study the deviations from the average value of each single region in order to reduce the bias of the starting knowledge stock. Thus, if we look at the dynamics of our sample, related to the distribution of human capital and the relevance of innovations, we can observe very different patterns between lagging and leading innovative European regions. We classified knowledge-intensive regions (Innovation Leaders and Strong Innovators) and less innovative regions (Moderate Innovators and Modest Innovators) using the Regional Innovation Scoreboard (RIS) provided by the European Commission (European Commission, 2016; De Noni et al., 2018). Less innovative or peripheral regions show higher increments of human capital (around 27\% in the period analysed) than the knowledge-intensive regions (around 16\%) in front of an opposite distribution of the number of citations (technological relevance) per patent in which the knowledge-intensive regions have much higher increments. The negative sign of human capital could also signal a different quality in tertiary education studies (lower in less innovative regions) and/or different effects of tertiary education subjects on innovation relevance. The latter is coherent with regional policies on vocational training and promotion of science, technology, engineering, and mathematics (STEM) fields.

This rationale is also supported by the results of the pooled OLS regression in which the starting regional levels are considered and also by the correlation matrix in Table 2 . In the pooled regression models both human capital and R\&D investments show positive and statistically significant coefficients. The pooled OLS results are available upon request.

In contrast, in terms of individual effects, regions with positive variations of manufacturing activities with respect to their mean show a superior technological progress relevance. In regions characterized by the presence of a large manufacturing base, the adoption and diffusion of new technologies seem to be facilitated, because manufacturing is typically more inclined to innovate through the exploitation of new patented technologies than other sectors (Hipp and Grupp, 2005; Marrocu et al., 2013). Finally, regions with higher increments of population density report lower levels of technological progress relevance. Even though urbanization economies are expected to better support regional innovation performance, increased urbanization may lead to negative externalities due to congestion costs, unskilled workers and immigrant inflows rather than talents, oversupply of labour, higher cost of living and insufficient infrastructure investments worsening the quality and value of patents (Dijkstra et al., 2013).

As previously observed in the results coming from the analysis of drivers for technological progress intensity, all models confirm the importance of spatial dependence on the technological progress relevance. The positive and significant lambda-coefficient (spatial lag dependence) means that being located in a high-quality innovative geographical context is likely to promote the adoption and diffusion of the technologies coming from neighbouring regions (Castaldi et al., 2015).

Finally, we tested the robustness of our results using different time windows of the dependent variables, and alternative model specifications. First, we used a 5-year time window instead of a 3-year time window for our dependent variables. The results of these analyses, reported in Appendix A, are consistent with those presented in Table 3. Second, we checked the robustness of our results by estimating fixed effects panel models without spatial dependences but using clustered standard errors at regional and country levels. Also, in this case, the results of the analyses were qualitatively similar to those presented here and are available upon request.

Table 3

Spatial fixed effects regression model results (3-year window lag).

\begin{tabular}{|c|c|c|c|c|c|c|c|c|c|c|}
\hline \multirow[t]{3}{*}{ Dependent variables } & \multicolumn{10}{|c|}{ Spatial panel fixed effects lag models } \\
\hline & \multicolumn{5}{|c|}{ Tech. progress intensity } & \multicolumn{5}{|c|}{ Tech. progress relevance } \\
\hline & Model 1a & Model 2a & Model 3a & Model 4a & Model 5a & Model 1b & Model 2b & Model 3b & Model 4b & Model 5b \\
\hline Lambda (spatial lag) & $\begin{array}{l}0.412 \\
(0.022)^{* * * *}\end{array}$ & $\begin{array}{l}0.411 \\
(0.022) * * *\end{array}$ & $\begin{array}{l}0.418 \\
(0.022)^{* * *}\end{array}$ & $\begin{array}{l}0.423 \\
(0.022) * * *\end{array}$ & $\begin{array}{l}0.422 \\
(0.022) * * *\end{array}$ & $\begin{array}{l}0.307 \\
(0.023)^{* * *}\end{array}$ & $\begin{array}{l}0.292 \\
(0.023)^{* * * *}\end{array}$ & $\begin{array}{l}0.307 \\
(0.023)^{* * *}\end{array}$ & $\begin{array}{l}0.295 \\
(0.023)^{* * *}\end{array}$ & $\begin{array}{l}0.306 \\
(0.023)^{* * * *}\end{array}$ \\
\hline \multicolumn{11}{|l|}{ Explanatory variables } \\
\hline Tech. knowledge base & & $\begin{array}{l}0.009 \\
(0.002) * * *\end{array}$ & & & & & $\begin{array}{l}-0.051 \\
(0.010)^{* * *}\end{array}$ & & & \\
\hline Tech. cumulativeness & & & $\begin{array}{l}0.002 \\
(0.003)\end{array}$ & & & & & $\begin{array}{l}-0.104 \\
(0.017)^{* * *}\end{array}$ & & \\
\hline Tech. diversification & & & & $\begin{array}{l}0.014 \\
(0.011)\end{array}$ & & & & & $\begin{array}{l}-0.120 \\
(0.042)^{* *}\end{array}$ & \\
\hline Tech. relatedness & & & & & $\begin{array}{l}0.001 \\
(0.000)^{* *}\end{array}$ & & & & & $\begin{array}{l}0.003 \\
(0.002)^{*}\end{array}$ \\
\hline \multicolumn{11}{|l|}{ Control variables } \\
\hline$R \& D$ expenditures & $\begin{array}{l}0.920 \\
(0.170)^{* * *}\end{array}$ & $\begin{array}{l}0.871 \\
(0.170)^{* * *}\end{array}$ & $\begin{array}{l}0.921 \\
(0.170)^{* * * *}\end{array}$ & $\begin{array}{l}0.918 \\
(0.170)^{* * *}\end{array}$ & $\begin{array}{l}0.887 \\
(0.170)^{* * *}\end{array}$ & $\begin{array}{l}-0.233 \\
(0.873)\end{array}$ & $\begin{array}{l}0.060 \\
(0.872)\end{array}$ & $\begin{array}{l}-0.239 \\
(0.867)\end{array}$ & $\begin{array}{l}-0.194 \\
(0.872)\end{array}$ & $\begin{array}{l}-0.328 \\
(0.875)\end{array}$ \\
\hline Human capital & $\begin{array}{l}0.000 \\
(0.000)\end{array}$ & $\begin{array}{l}0.000 \\
(0.000)\end{array}$ & $\begin{array}{l}0.000 \\
(0.000)\end{array}$ & $\begin{array}{l}0.000 \\
(0.000)\end{array}$ & $\begin{array}{l}0.000 \\
(0.000)\end{array}$ & $\begin{array}{l}-0.015 \\
(0.001)^{* * *}\end{array}$ & $\begin{array}{l}-0.011 \\
(0.002)^{* * *}\end{array}$ & $\begin{array}{l}-0.013 \\
(0.002)^{* k *}\end{array}$ & $\begin{array}{l}-0.014 \\
(0.002)^{* * *}\end{array}$ & $\begin{array}{l}-0.016 \\
(0.002)^{* * *}\end{array}$ \\
\hline Manuf. specialization & $\begin{array}{l}-0.001 \\
(0.000)^{*}\end{array}$ & $\begin{array}{c}-0.001 \\
(0.000)^{*}\end{array}$ & $\begin{array}{c}-0.001 \\
(0.000)^{*}\end{array}$ & $\begin{array}{c}-0.001 \\
(0.000)^{*}\end{array}$ & $\begin{array}{c}-0.001 \\
(0.000)^{*}\end{array}$ & $\begin{array}{l}0.007 \\
(0.002)^{* * *}\end{array}$ & $\begin{array}{l}0.008 \\
(0.002)^{* * * *}\end{array}$ & $\begin{array}{l}0.007 \\
(0.002)^{* * *}\end{array}$ & $\begin{array}{l}0.007 \\
(0.002)^{* * *}\end{array}$ & $\begin{array}{l}0.007 \\
(0.002)^{* * *}\end{array}$ \\
\hline Pop. Density & $\begin{array}{l}0.011 \\
(0.028)\end{array}$ & $\begin{array}{l}0.022 \\
(0.028)\end{array}$ & $\begin{array}{l}0.011 \\
(0.028)\end{array}$ & $\begin{array}{l}0.012 \\
(0.028)\end{array}$ & $\begin{array}{l}0.016 \\
(0.028)\end{array}$ & $\begin{array}{l}-0.372 \\
(0.147)^{*}\end{array}$ & $\begin{array}{l}-0.440 \\
(0.147)^{* *}\end{array}$ & $\begin{array}{l}-0.341 \\
(0.146)^{*}\end{array}$ & $\begin{array}{l}-0.371 \\
(0.147)^{*}\end{array}$ & $\begin{array}{l}-0.360 \\
(0.147)^{* *}\end{array}$ \\
\hline No. of observations & 2421 & 2421 & 2421 & 2421 & 2421 & 2421 & 2421 & 2421 & 2421 & 2421 \\
\hline EU NUTS-2 regions & 269 & 269 & 269 & 269 & 269 & 269 & 269 & 269 & 269 & 269 \\
\hline No. of panels & 9 & 9 & 9 & 9 & 9 & 9 & 9 & 9 & 9 & 9 \\
\hline R squared & 0.843 & 0.855 & 0.845 & 0.843 & 0.851 & 0.711 & 0.714 & 0.715 & 0.712 & 0.712 \\
\hline GLS residual variance & 0.0067 & 0.0065 & 0.0067 & 0.0067 & 0.0066 & 0.0152 & 0.0150 & 0.0150 & 0.0151 & 0.0151 \\
\hline Moran I & $12.99^{* * *}$ & $12.99^{* * *}$ & $12.99^{* * *}$ & $12.99 * * *$ & $12.99^{* * *}$ & $5.73^{* * *}$ & $5.73^{* * *}$ & $5.73^{* * *}$ & $5.73^{* * *}$ & $5.73^{* * *}$ \\
\hline LM-lag & $321.25^{* * *}$ & $293.83^{* * *}$ & $318.93^{* * *}$ & $317.65^{* * *}$ & $310.18^{* * *}$ & $197.47^{* * *}$ & $177.02 * * *$ & $181.54^{* *}$ & $196.49^{* * *}$ & $197.36^{* * *}$ \\
\hline RLM-lag & $12.39^{* * *}$ & $28.09^{* * *}$ & $13.99^{* * *}$ & $15.34^{* * *}$ & $20.01 * * *$ & $40.85^{* * *}$ & $25.28^{* * *}$ & $35.04^{* * *}$ & $33.12^{* * *}$ & $46.28^{* * *}$ \\
\hline Hausman $\chi(\mathrm{df})$ & $268(4)^{* * *}$ & $240(5)^{* * *}$ & $278(5)^{* * *}$ & $268(5)^{* * *}$ & $178(5)^{* * *}$ & $238(4)^{* * *}$ & $276(5)^{* * *}$ & $157(5)^{* * *}$ & $205(5)^{* * *}$ & $231(5)^{* * *}$ \\
\hline Max VIF & 1.62 & 2.17 & 1.69 & 1.63 & 1.75 & 1.62 & 2.17 & 1.69 & 1.68 & 1.75 \\
\hline
\end{tabular}

Notes: Standard errors are in parentheses. Significance levels are ${ }^{* *} \mathrm{p}<0.001,{ }^{* *} \mathrm{p}<0.01,{ }^{*} \mathrm{p}<0.10$. 


\section{Discussion and conclusions}

This study investigates how the knowledge space of regions influences their technological progress. On the theoretical side, the originality of our research relies on 1) accounting for the marginal effect of the different features of a regional knowledge space, and 2) accounting for the two main features of regional technological progress (intensity and relevance). The most interesting results are the following. The size of the regional knowledge base affects in a radically opposite way the intensity and relevance of technological progress (a); technological cumulativeness $(b)$ and diversification (c) negatively affect the relevance; finally, technological relatedness affects positively both the intensity and relevance of the technological progress $(d)$.

The first result (a), on the divergent effect of the size of the regional knowledge on the two main features of the technological progress can be commented on as follows. The positive impact of the size of the regional knowledge base on the intensity of the technological progress is well supported by previous contributions, and therefore aligns with previous results (Ahuja and Katila, 2001; Smith et al., 2005; Tria et al., 2014; Castaldi et al., 2015). There is a path-dependent process and a scale effect in the innovation trajectory of regions. The development and diffusion of a regional innovation culture, favoured by the presence of numerous innovative firms and private and public organizations offering knowledge intensive support services, foster the knowledge creation process and enable, through local contamination processes, the achievement of economies of scale at the regional level. This self-reinforcing process determines a successful path in terms of intensity of the technological progress, as depicted in the literature on regional innovation systems (Cooke, 2001; Asheim and Gertler, 2005). The negative impact of the size of the regional knowledge base on the relevance of the technological progress can be linked to exhaustion processes, which are typical of advanced regions that are starting to face a decline in their role as technological leaders. The focus on exploitation rather than exploration processes might underestimate the value of searching for new venues of research and the investment in new "risky business", which might lead to impactful innovative output and potential radical innovations. In business literature, there is a metaphor for illustrating this attitude, that of the "cash cows" - companies whose corporate strategy tends to maximize the resources possessed, even if this behaviour configures as being myopic, mostly in dynamic and fast evolving sectors.

The second result $(b)$ is strongly related to the previous one. The negative effect of cumulativeness on innovation relevance suggests that the more the technological trajectory of the region is built upon a vast array of consolidated technologies, and, therefore, generally speaking, path-dependent, the less the probability that the output of the innovation effort is a breakthrough and further exploitable in different areas of applications.

The first two results ( $a$ and $b$ ) highlight the need to address a regional policy framework able not only to sustain the innovation efforts of the "champions", but also to identify and develop specific technological niches in which to invest through ad hoc industrial plans, which may also include initiatives to sustain innovative entrepreneurships. Moreover, as claimed by Miguelez and Moreno (2018), analysis of the geographical dimension of technological cumulativeness might be conducive to important choices, on the matter of which can be the more useful inter-regional and global collaborations to be sustained, as a complementary asset to the exploitation of regional knowledge sources.

The third finding $(c)$ is more surprising, because of the presence of a vast literature that sustains the benefits of diversification on innovation performance (Rodan and Galunic, 2004; Frenken et al., 2007; Nemet and Johnson, 2012; Tavassoli and Carbonara, 2014; Rosenzweig, 2017) - yet does not distinguish between the intensity and relevance of the technological progress. Our results offer an important contribution by showing that diversification negatively influences the relevance of the regional technological progress. A note is due here. We define diversification not in terms of breadth of the current regional knowledge base, but in terms of the capacity of the region to access and recombine a number of diversified internal and external regional knowledge sources. In this matter, the negative impact of diversification can be understood as a low capability of regions to have access to "meaningful" knowledge sources. In other words, the fact that a region develops technologies that are the result of a pool of diverse knowledge sources does not mean that the one that is developed suits the need of the production processes that are conducted in the region and that can find opportunities for further development and transformation in valuable products. This raises the need for regions to encourage a better interaction between knowledge sources and knowledge users, enhancing the collaborations between firms, local research organizations and universities through, for instance, technological transfer offices (TTOs) or new forms of hybrid organizations. However, TTOs have some limitations, mainly because in order to be effective they should handle specific managerial capacities, should count on a suitable mix of staff members with complementary competences, and last, but not least, should enrol licensing professionals with strong marketing and business skills (Siegel et al., 2003); on the contrary, in most cases, TTOs focus on administrative issues without attempting to identify the better and faster strategies to market inventions. Haeussler and Colyvas (2011) and Perkmann et al. (2013) claim that TTOs' organizational structures and cultures are often not well aligned. Therefore, TTOs should play a potentially increasing role in evaluating the quality of inventions and better identifying potential technological applications. A better support from hybrid organizations in developing a deeper analysis of the three helixes of university, industry, and government are desired.

Fourth $(d)$, the research findings show that technological relatedness is the key factor influencing the technological progress of regions, either measured in terms of intensity or relevance. This evidence provides support for the interpretative framework put forward by the Utrecht school, led by members of the Department of Human Geography and Planning (Ron Boschma, Koen Frenken, Frank van Oort - among others), who in the early $2000 \mathrm{~s}$ started to devote attention to the neglected relationship between variety and economic development in regions. Focusing on innovation performance, the combination of related technologies allows the development of more familiar technological trajectories, produces general innovation benefits (Ponds et al., 2010), increases the likelihood of related knowledge spillovers (Quatraro and Usai, 2017), and positively affects innovation quantity (Tavassoli and Carbonara, 2014) and quality performance (Miguelez and Moreno, 2018). However, the insignificance of relatedness on innovation relevance as a result of our five-year lagged models (shown in Appendix A), confirms the conflicting results of Castaldi et al. (2015) and suggests it might be deficient in systematically stimulating and supporting radical and path-breaking innovation processes.

This result stresses the European Union's current regional innovation policy concept of smart specialization, which defines "a bottom-up policy approach based on the idea that regions should leverage their existing capabilities to develop and secure comparative advantage in related high-value-added activities" (Balland et al., 2017, p. 24). In this light, as suggested by Neffke et al. (2011), regions should strengthen their industrial cohesion by entering industries which are related to preexisting industries and by exiting industries which are technologically peripheral. Investing in related industries, on the one hand, may increase the number of collaboration opportunities and the number of knowledge spillovers, and on the other hand, may foster invention adoption across regional industries where these technologies could be applied. In addition, because of the uncertainty of valuable 
breakthrough inventions, regions should support a less risky and more systematic innovation process able to stimulate interconnections and cross-fertilization opportunities by focusing on the own knowledge domain and on closer technological trajectories to be explored.

Consequently, an immediate policy implication concerns the direction of the R\&D expenditure in regions, which might be chosen coherently with the industrial structure and the possible areas of interactions across sectors. New or existing specific infrastructures should be assigned to provide information on the cognitive proximity between technologies and should be in charge of monitoring possible cross-fertilization between technologies, with the final objective of enlightening local firms on potential partnerships and/or merger and acquisition processes for acquiring complementary knowledge and capabilities.

Finally, even though our analysis does not explore the differences between knowledge-intensive and lagging behind regions - and this is clearly a promising future research trajectory - we believe no one-sizefits-all solution exists, and, as the smart specialization agenda claims (Foray, 2009), the technological trajectories of regions must be shaped around past and present resource endowments and future objectives. In particular, a twofold technological trajectory might discriminate knowledge-intensive territories by lagging-behind ones. Since it has been theorized that the more socio-economically developed regions are more conducive to knowledge-intensive, innovative activity (Rodriguez-Pose and Wilkie, 2017), they might be more suited to capitalize on their past R\&D expenditure, by exploiting core capabilities alongside a technological trajectory that follows a relatedness-based specialization strategy. This is the recommendation that is suggested by the statistics illustrated in the previous section, which show how the technological specialization, together with the relatedness, boosts the technological progress relevance. Stemming from the observation that more is not better or, similarly, quantity is not relevant, a developed region with a consolidated technological trajectory should deploy its knowledge base not by increasing the number of patents, but by maximizing the diffusion of the innovations that depart from the application of its patents. In contrast, lagging-behind regions should invest more in R\&D in order to establish a feasible knowledge space and reach a level of technological progress intensity that allows them to compete with knowledge-intensive regions, as also claimed by Rodríguez-Pose (2001). Nevertheless, our results suggest using caution when adopting the same policy for developed regions, because, in this realm, the marginal effects of an increase in innovation output might be lower than that of investing in expanding the potential for new applications of pre-existing inventive output. Moreover, since the proximity to knowledge-intensive regions contributes positively to innovation intensity and relevance - as the spatial parameters indicate - a crossregional technological fertilization pattern is desired, where knowledge flows from developed to lagging-behind regions is enhanced (De Noni et al., 2018).

In this research study, a number of limitations need to be considered. Firstly, patents, while being a good proxy for technological advancement in a region, are only a part of it and represent only innovation input/throughput. However, they represent a very homogeneous measure of technological novelty across regions. Secondly, coinvented patents are equally fractionalized for the number of inventors, even if some of them may be responsible for the majority of patent applications. Thirdly, some specific forms of knowledge spillover might not be properly captured by using only geographical distance (referred to as a contiguity-based weights matrix in the regression models) without considering other forms of distance, such as social, cognitive or institutional (Paci et al., 2014). Fourthly, although the IPC is acceptable and clear for our purpose, it has been developed for reasons other than providing scholars with a complete picture of the knowledge bases and variety of organizations and regions (Alcacer and Gittelman, 2006).

Nevertheless, we encourage further investigation into the relationship between the specific technological investments of a region and the magnitude and impact of its innovation performance in terms of technological progress. Furthermore, future research could attempt to draw the dynamics of the technological progress in the European regions by distinguishing the contribution of different types of organization (e.g., small and medium sized enterprises, large firms, multinationals and public research organizations). The availability of more comprehensive datasets, providing further information on patents, could allow future research to extend and improve our work.

\section{Acknowledgements}

The authors' names are ordered alphabetically. We acknowledge financial support from the EU's 7th Framework Programme for research, technological development and demonstration under grant agreement no 320131 (SmartSpec). We thank participants at the SMS extension conference in Padova: Innovation, Entrepreneurship, and Invention Networks, June, 8-9 2016; AAG Annual Meeting, San Francisco, March 29 - April 2, 2016; GEOINNOV Conference, Toulouse, January 28th-30th, 2016; the Smartspec Thematic Workshop, Padova, November 13th-14th, 2015, for their valuable comments on earlier drafts. We are grateful to the editor, Keld Laursen, and the three anonymous reviewers, who provided excellent guidance throughout the review process. The usual disclaimer applies. 


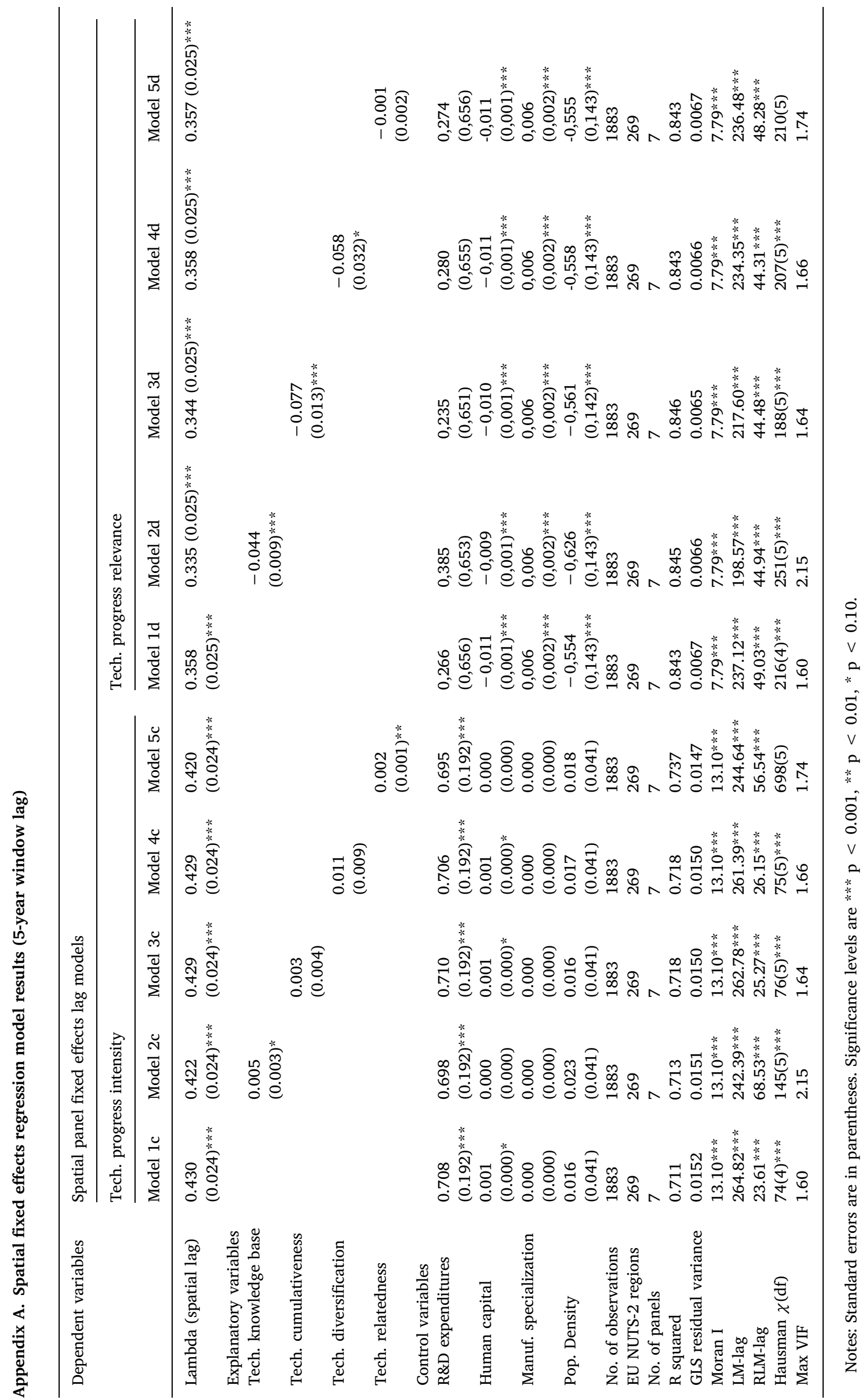




\section{References}

Acs, Z., Armington, C., 2004. Employment growth and entrepreneurial activity in cities. Reg. Stud. 38 (8), 911-927.

Acs, Z.J., Anselin, L., Varga, A., 2002. Patents and innovation counts as measures of regional production of new knowledge. Res. Policy 31 (7), 1069-1085.

Aghion, P., Howitt, P., Howitt, P.W., Brant-Collett, M., García-Peñalosa, C., 1998. Endogenous Growth Theory. MIT Press.

Ahuja, G., Katila, R., 2001. Technological acquisitions and the innovation performance of acquiring firms: a longitudinal study. Strateg. Manage. J. 22 (3), 197-220.

Ahuja, G., Lampert, C.M., 2001. Entrepreneurship in the large corporation: a longitudinal study of how established firms create breakthrough inventions. Strateg. Manage. J. 22 (6-7), 521-543.

Alcacer, J., Gittelman, M., 2006. Patent citations as a measure of knowledge flows: the influence of examiner citations. Rev. Econ. Stat. 88 (4), 774-779.

Anselin, L., 1988. Spatial Econometrics: Methods and Models. Kluwer Academic, Dordrecht.

Arthur, W.B., 1996. Increasing returns and the new world of business. Harv. Bus. Rev. 74 (4), 100-109.

Arthur, W.B., 2007. The structure of invention. Res. Policy 36 (2), 274-287.

Asheim, B.T., 1996. Industrial districts as 'Learning regions': a condition for prosperity. Eur. Plan. Stud. 4, 379-400.

Asheim, B., Gertler, M.S., 2005. The geography of innovation: regional innovation systems. The Oxford Handbook of Innovation. pp. 291-317.

Asheim, B.T., Moodysson, J., Tödtling, F., 2011. Constructing regional advantage: towards state-of-the-art regional innovation system policies in Europe? Eur. Plan. Stud. 19 (7), 1133-1139.

Audretsch, D.B., Vivarelli, M., 1996. Firms size and R\&D spillovers: evidence from Italy. Small Bus. Econ. 8 (3), 249-258.

Balland, P.-A., 2017. Economic Geography in R: Introduction to the EconGeo Package. Papers in Evolutionary Economic Geography. Utrecht University.

Balland, P.-A., Rigby, D., Boschma, R., 2015. The technological resilience of US cities. Camb. J. Reg. Econ. Soc. 8 (2), 167-184.

Balland, P.-A., Boschma, R.A., Crespo, J., Rigby, D.L., 2017. Smart Specialization Policy in the EU: Relatedness, Knowledge Complexity and Regional Diversification. downloaded on 3 March 2018 from. http://econ.geo.uu.nl/peeg/peeg1717.pdf).

Banerjee, P.M., Cole, B.M., 2010. Breadth-of-impact frontier: how firm-level decisions and selection environment dynamics generate boundary-spanning inventions. Technovation 30 (7), 411-419.

Basile, R., Capello, R., Caragliu, A., 2012. Technological interdependence and regional growth in Europe: proximity and synergy in knowledge spillovers. Papers Reg. Sci. 91 (4), 697-722.

Benson, C.L., Magee, C.L., 2012. A framework for analyzing the underlying inventions that drive technical improvements in a specific technological field. Eng. Manage. Res. 1 (1), 2.

Bierly, P., Chakrabarti, A., 1996. Generic knowledge strategies in the US pharmaceutical industry. Strateg. Manage. J. 17 (S2), 123-135.

Bishop, P., Gripaios, P., 2010. Spatial externalities, relatedness and sector employment growth in Great Britain. Reg. Stud. 44 (4), 443-454.

Boschma, R., Iammarino, S., 2009. Related variety, trade linkages, and regional growth in Italy. Econ. Geogr. 85, 289-311.

Boschma, R.A., Lambooy, J.G., 1999. Evolutionary economics and economic geography. J. Evol. Econ. 9 (4), 411-429.

Boschma, R., Eriksson, R., Lindgren, U., 2009. How does labour mobility affect the performance of plants? The importance of relatedness and geographical proximity. J. Econ. Geogr. 9 (2), 169-190.

Boschma, R., Minondo, A., Navarro, M., 2012. Related variety and regional growth in Spain. Papers Reg. Sci. 91 (2), 241-256.

Boschma, R., Balland, P.-A., Kogler, D.F., 2014. Relatedness and technological change in cities: the rise and fall of technological knowledge in US metropolitan areas from 1981 to 2010. Ind. Corporate Change 24 (1), 223-250.

Brachert, M., Kubis, A., Titze, M., 2011. Related Variety, Unrelated Variety and Regional Functions: Identifying Sources of Regional Employment Growth in Germany from 2003 to 2008. IWH-Diskussionspapiere No. 2011, 15. Halle Institute for Economic Research (IWH), Halle.

Braczyk, H.J., Cooke, P., Heidenreich, M., 1998. Regional Innovation Systems: the Role of Governance in a Globalized World. UCL Press, London.

Breschi, S., 2000. The geography of innovation: a cross-sector analysis. Reg. Stud. 34 (3), 213-229.

Breschi, S., Malerba, F., Orsenigo, L., 2000. Technological regimes and schumpeterian patterns of innovation. Econ. J. 110 (463), 388-410.

Button, K., 2011. The economist's perspective on regional endogenous development. In: Stimson, R.J., Stough, R.R., Nijkamp, P. (Eds.), Endogenous Regional Development: Perspectives, Measurement and Empirical Investigation. Edward Elgar, Cheltenham, pp. 20-39.

Capello, R., 2009. Spatial spillovers and regional growth: a cognitive approach. Eur. Plan. Stud. 17, 639-658.

Castaldi, C., Frenken, K., Los, B., 2015. Related variety, unrelated variety and technological breakthroughs: an analysis of US state-level patenting. Reg. Stud. 49 (5), 767-781.

Castells, M., 1996. The Rise of the Network Society: The Information Age: Economy, Society and Culture Vol. 1 Blackwell, Oxford.

Cheshire, P., Magrini, S., 2000. Endogenous processes in European regional growth: convergence and policy. Growth Change 31 (4), 455-479.

Cohen, W.M., Levinthal, D.A., 1990. Absorptive capacity: a new perspective on learning and innovation. Admin. Sci. Q. 35 (1), 128-152.

Cooke, P., 2001. Regional innovation systems, clusters, and the knowledge economy. Ind. Corporate Change 10 (4), 945-974.

Cooke, P., 2002. Knowledge Economies Clusters, Learning and Cooperative Advantage. Routledge, London.

Cooke, P., Uranga, M., Etxebarria, G., 1997. Regional innovation systems: institutional and organisational dimensions. Res. Policy 26, 475-491.

Cortinovis, N., Van Oort, F., 2015. Variety, economic growth and knowledge intensity of European regions: a spatial panel analysis. Ann. Reg. Sci. 55 (1), 7-32.

Cortinovis, N., Xiao, J., Boschma, R., van Oort, F.G., 2017. Quality of government and social capital as drivers of regional diversification in Europe. J. Econ. Geogr. 17, 1179-1208.

Crescenzi, R., Rodríguez-Pose, A., Storper, M., 2012. The territorial dynamics of in novation in China and India. J. Econ. Geogr. 12 (5), 1055-1085.

De Carolis, D.M., Deeds, D.L., 1999. The impact of stocks and flows of organizational knowledge on firm performance: an empirical investigation of the biotechnology industry. Strateg. Manage. J. 20 (10), 953-968.

De Noni, I., Ganzaroli, A., Orsi, L., 2017. The impact of intra- and inter-regional knowledge collaboration and technological variety on the knowledge productivity of European regions. Technol. Forecasting Soc. Change 117, 108-118.

De Noni, I., Orsi, L., Belussi, F., 2018. The role of collaborative networks in supporting the innovation performances of lagging-behind European regions. Res. Policy 47 (1), $1-13$.

Dettori, B., Marrocu, E., Paci, R., 2012. Total factor productivity, intangible assets and spatial dependence in the European regions. Reg. Stud. 46 (10), 1401-1416.

Dijkstra, L., Garcilazo, E., McCann, P., 2013. The economic performance of European cities and city regions: Myths and realities. Eur. Plan. Stud. 21 (3), 334-354.

Dosi, G., 1982. Technological paradigms and technological trajectories: a suggested in terpretation of the determinants and directions of technical change. Res. Policy 11 (3), 147-162.

Dosi, G., Freeman, C., Nelson, R., Silverberg, G., Soete, L. (Eds.), 1988. Technical Change and Economic Theory. Pinter Publishers, London.

Essletzbichler, J., 2015. Relatedness, industrial branching and technological cohesion in US metropolitan areas. Reg. Stud. 49 (5), 752-766.

EUCO, 2010. European Council Conclusions 17 June 2010. EUCO 13/10, Brussels.

European Commission, 2016. Regional Innovation Scoreboard. 1-64. European Commission, Bruxelles 10.2873/84730.

European Commission (EC), 2010. Europe 2020: a Strategy for Smart, Sustainable and Inclusive Growth. Working Paper \{COM (2010) 2020\}.

Feldman, M.P., 1994. The Geography of Innovation. Kluwer Academic Publishers, Boston.

Fleming, L., 2001. Recombinant uncertainty in technological search. Manage. Sci. 47 (1), $117-132$.

Fleming, L., Sorenson, O., 2004. Science as a map in technological search. Strateg. Manage. J. 25 (8-9), 909-928.

Foray, D., 2009. In: Pontikakis, D., Kyriakou, D., van Bavel, R. (Eds.), Understanding Smart Specialisation. The Question of R\&D Specialisation, JRC, European Commission, Directoral General for Research, Brussels, pp. 19-28.

Fornahl, D., Broekel, T., Boschma, R., 2011. What drives patent performance of German biotech firms? The impact of R\&D subsidies, knowledge networks and their location. Papers Reg. Sci. 90 (2), 395-418.

Frenken, K., Van Oort, F., Verburg, T., 2007. Related variety, unrelated variety and regional economic growth. Reg. Stud. 41 (5), 685-697.

Frenz, M., Prevezer, M., 2012. What can CIS data tell us about technological regimes and persistence of innovation? Ind. Innov. 19 (4), 285-306.

Gambardella, A., Harhoff, D., Verspagen, B., 2008. The value of European patents. Eur. Manage. Rev. 5, 85-89.

Gilsing, V., Nooteboom, B., Vanhaverbeke, W., Duysters, G., van den Oord, A., 2008. Network embeddedness and the exploration of novel technologies: technological distance, betweenness centrality and density. Res. Policy 37 (10), 1717-1731.

Greene, W.H., 2008. The econometric approach to efficiency analysis. In: Fried, H.O., Knox Lovell, C.A., Schmidt, S.S. (Eds.), The Measurement of Productive efficiency and Productivity Growth. Oxford University Press, New York, pp. 92-250.

Grillitsch, M., Tödtling, F., Höglinger, C., 2015. Variety in knowledge sourcing, geography and innovation: evidence from the ICT sector in Austria. Papers Reg. Sci. 94 (1), 25-43.

Grossman, G.M., Helpman, E., 1991. Trade, knowledge spillovers, and growth. Eur. Econ. Rev. 35 (2-3), 517-526.

Haeussler, C., Colyvas, J.A., 2011. Breaking the ivory tower: academic entrepreneurship in the life sciences in UK and Germany. Res. Policy 40 (1), 41-54.

Hall, P.A., Soskice, D., 2003. Varieties of capitalism and institutional change: a response to three critics. Comp. Eur. Politics 1 (2), 241-250.

Hall, B.H., Jaffe, A.B., Trajtenberg, M., 2001. The NBER patent citation data file: lessons, insights and methodological tools (No. w8498). Nat. Bur. Econ. Res.

Hall, B.H., Jaffe, A.B., Trajtenberg, M., 2005. Market value and patent citations. Rand. J. Econ. 36 (1), 16-38.

Harhoff, D., Wagner, S., 2009. The duration of patent examination at the European paten office. Manage. Sci. 55 (12), 1969-1984.

Harhoff, D., Scherer, F.M., Vopel, K., 2003. Citations, family size, opposition and the value of patent rights. Res. Policy 32 (8), 1343-1363.

Harrison, J., 2006. Re-reading the new regionalism: a sympathetic critique. Space Polity $10(1), 21-46$

Harrison, J., 2007. From competitive regions to competitive city-regions: a new orthodoxy, but some old mistakes. J. Econ. Geogr. 7 (3), 311-332.

Hartog, M., Boschma, R., Sotarauta, M., 2012. The impact of related variety on regional employment growth in Finland 1993-2006: high-tech versus medium/low-tech. Ind. Innov. 19 (6), 459-476. 
Hassink, R., 2001. The learning region: a fuzzy concept or a sound theoretical basis for modern regional innovation policies? Zeitschrift für Wirtschaftsgeographie 45 (1), 219-230.

Hill, C.W., Rothaermel, F.T., 2003. The performance of incumbent firms in the face of radical technological innovation. Acad. Manage. Rev. 28 (2), 257-274.

Hipp, C., Grupp, H., 2005. Innovation in the service sector: the demand for service-specific innovation measurement concepts and typologies. Res. Policy 34 (4), 517-535.

Hofstede, G., 1984. Culture's Consequences: International Differences in Work-Related Values Vol. 5 Sage, Newbury Park.

Hudson, R., 1999. The learning economy, the learning firm and the learning region. A sympathetic critique of the limits to learning. Eur. Urban Reg. Stud. 6 (1), 59-72.

Iammarino, S., 2005. An evolutionary integrated view of regional systems of innovation: concepts, measures and historical perspectives. Eur. Plan. Stud. 13 (4), 497-519.

Jacobs, J., 1969. The Economy of Cities. Vintage, New York.

Jaffe, A.B., de Rassenfosse, G., 2017. Patent citation data in social science research: overview and best practices. J. Assoc. Inf. Sci. Technol. 68 (6), 1360-1374.

Kaplan, S., Vakili, K., 2015. The double-edged sword of recombination in breakthrough innovation. Strateg. Manage. J. 36 (10), 1435-1457.

Kogler, D.F., Rigby, D.L., Tucker, I., 2013. Mapping knowledge space and technological relatedness in US cities. Eur. Plan. Stud. 21 (9), 1374-1391.

Kogut, B., Zander, U., 1992. Knowledge of the firm, combinative capabilities, and the replication of technology. Org. Sci. 3 (3), 383-397.

Lane, P.J., Koka, B.R., Pathak, S., 2006. The reification of absorptive capacity: a critical review and rejuvenation of the construct. Acad. Manage. Rev. 31 (4), 833-863.

Lanjouw, J.O., Schankerman, M., 2004. Patent quality and research productivity: measuring innovation with multiple indicators. Econ. J. 114 (495), 441-465.

Lee, K., Lim, C., 2001. Technological regimes, catching-up and leapfrogging: findings from the korean industries. Res. Policy 30 (3), 459-483.

Lee, S.Y., Florida, R., Gates, G., 2010. Innovation, human capital, and diversity. Int. Rev. Public Administration 14 (3), 13-24.

Lee, J.S., Park, J.H., Bae, Z.T., 2017. The effects of licensing-in on innovative performance in different technological regimes. Res. Policy 46 (2), 485-496.

Lundvall, B.Ä., Johnson, B., 1994. The learning economy. J. Ind. Stud. 1 (2), 23-42.

MacKinnon, D., Cumbers, A., Chapman, K., 2002. Learning, innovation and regiona development: a critical appraisal of recent debates. Prog. Hum. Geogr. 26 (3), 293-311.

Malerba, F., Orsenigo, L., 1993. Technological regimes and firm behavior. Ind. Corporate Change 2, 45-74.

Malerba, F., Orsenigo, L., 1996. Schumpeterian patterns of innovation are technologyspecific. Res. Policy 25 (3), 451-478.

Mameli, F., Iammarino, S., Boschma, R., 2012. Regional variety and employment growth in Italian labour market areas: services versus manufacturing industries. Papers Evol. Econ. Geogr. 12.

March, J.G., 1991. Exploration and exploitation in organizational learning. Org. Sci. 2 (1), 71-87.

Marrocu, E., Paci, R., Usai, S., 2013. Proximity, networking and knowledge production in Europe: what lessons for innovation policy? Technol. Forecasting Soc. Change 80, 1484-1498.

Martin, R.L., Sunley, P., 2006. Path dependence and regional economic evolution. J. Econ. Geogr. 6, 395-437.

Merton, R.K., 1988. The Matthew effect in science, II: cumulative advantage and the symbolism of intellectual property. Isis 79 (4), 606-623.

Miguelez, E., Moreno, R., 2018. Relatedness, external linkages and regional innovation in Europe. Reg. Stud. 52 (5), 688-701.

Miller, D.J., Fern, M.J., Cardinal, L.B., 2007. The use of knowledge for technological innovation within diversified firms. Acad. Manage. J. 50 (2), 307-325.

Morgan, K., 1997. The learning region: institutions, innovation and regional renewal. Reg. Stud. 31 (5), 491-503.

Neffke, F., Henning, M., Boschma, R., 2011. How do regions diversify over time? Industry relatedness and the development of new growth paths in regions. Econ. Geogr. 87 (3), $237-265$.

Nelson, R., Winter, S., 1982. An Evolutionary Theory of Economic Change. The Belknapp Press of Harvard University Press, Harvard.

Nemet, G.F., Johnson, E., 2012. Do important inventions benefit from knowledge originating in other technological domains? Res. Policy 41 (1), 190-200.

Nickell, S., 1981. Biases in dynamic models with fixed effects. Econometrica: J. Econ. Soc. 49 (6), 1417-1426.

Nooteboom, B., 2000. Learning and Innovation in Organizations and Economies. Oxford University Press, Oxford.

O'Brien, R.M., 2007. A caution regarding rules of thumb for variance inflation factors. Quality Quantity 41 (5), 673-690.

Paci, R., Usai, S., 2009. Knowledge flows across European regions. Ann. Reg. Sci. 43 (3), 669-690.

Paci, R., Marrocu, E., Usai, S., 2014. The complementary effects of proximity dimensions on knowledge spillovers. Spatial Econ. Anal. 9 (1), 9-30.

Pavitt, K., 1984. Sectoral patterns of technical change: towards a taxonomy and a theory. Res. Policy 13 (6), 343-375.

Peneder, M., 2010. Technological regimes and the variety of innovation behaviour: creating integrated taxonomies of firms and sectors. Res. Policy 39 (3), 323-334.

Perkmann, M., Tartari, V., McKelvey, M., Autio, E., Broström, A., D’Este, P., Fini, R. Geuna, A., Grimaldi, R., Hughes, A., Krabel, S., Kitson, M., Llerena, P., Lissoni, F., Salter, A., Sobrero, M., 2013. Academic engagement and commercialisation: a review of the literature on university-industry relations. Res. Policy 42 (2), 423-442.

Petralia, S., Balland, P.-A., Morrison, A., 2017. Climbing the ladder of technological development. Res. Policy 46 (5), 956-969.

Phene, A., Fladmoe-Lindquist, K., Marsh, L., 2006. Breakthrough innovations in the US biotechnology industry: the effects of technological space and geographic origin. Strateg. Manage. J. 27 (4), 369-388.

Plummer, P., Tonts, M., Martinus, K., 2014. Endogenous growth, local competitiveness and regional development: Western Australia's regional cities, 2001-2011. J. Econ. Soc. Policy 16 (1), 1-29.

Ponds, R., Van Oort, F., Frenken, K., 2010. Innovation, spillovers and university-industry collaboration: an extended knowledge production function approach. J. Econ. Geogr. 10 (2), 231-255.

Prabhu, J.C., Chandy, R.K., Ellis, M.E., 2005. The impact of acquisitions on innovation: poison pill, placebo, or tonic? J. Mark. 69 (1), 114-130.

Quatraro, F., 2010. Knowledge coherence, variety and economic growth: manufacturing evidence from Italian regions. Res. Policy 39 (10), 1289-1302.

Quatraro, F., Usai, S., 2017. Are knowledge flows all alike? Evidence from European regions. Reg. Stud. 51 (8), 1246-1258.

Rigby, D.L., 2015. Technological relatedness and knowledge space: entry and exit of U.S. Cities from patent classes. Reg. Stud. 49 (11), 1922-1937.

Rodan, S., Galunic, C., 2004. More than network structure: how knowledge heterogeneity influences managerial performance and innovativeness. Strateg. Manage. J. 25, $541-562$.

Rodriguez-Pose, A., Wilkie, C., 2017. Innovation and competitiveness in the periphery of Europe. In: Huggins, R., Thompson, P. (Eds.), Handbook of Regions and Competitiveness. Edward Elgar, Cheltenham, pp. 351-380.

Rodríguez-Pose, A., 2001. Is R\&D investment in lagging areas of Europe worthwhile? Theory and empirical evidence. Papers Reg. Sci. 80 (3), 275-295.

Romer, P.M., 1990. Endogenous technological change. J. Polit. Econ. 98 (5, Part 2), S71-S102.

Rosenzweig, S., 2017. The effects of diversified technology and country knowledge on the impact of technological innovation. J. Technol. Transf. 42 (3), 564-584.

Saviotti, P.P., 1996. Technological Evolution. Variety and the Economy. Elgar, Aldershot.

Saviotti, P.P., Frenken, K., 2008. Export variety and the economic performance of countries. J. Evol. Econ. 18 (2), 201-218.

Schumpeter, J.A., 1934. The Theory of Economic Development. Harvard Economic Studies, Cambridge.

Schumpeter, J.A., 1942. Capitalism, Socialism and Democracy. Harper, New York.

Sedita, S.R., De Noni, I., Pilotti, L., 2017. Out of the crisis: an empirical investigation of place-specific determinants of economic resilience. Eur. Plan. Stud. 25 (2), 155-180.

Siegel, D.S., Waldman, D., Link, A., 2003. Assessing the impact of organizational practices on the relative productivity of university technology transfer offices: an exploratory study. Res. Policy 32 (1), 27-48.

Singh, J., Fleming, L., 2010. Lone inventors as sources of breakthroughs: Myth or reality? Manage. Sci. 56 (1), 41-56.

Smith, K.G., Collins, C.J., Clark, K.D., 2005. Existing knowledge, knowledge creation capability, and the rate of new product introduction in high-technology firms. Acad. Manage. J. 48 (2), 346-357.

Stimson, R.J., Stough, R., Nijkamp, P., 2011. Endogenous Regional Development: Perspectives, Measurement and Empirical Investigation. Edward Elgar Publishing, Cheltenham.

Tavassoli, S., Carbonara, N., 2014. The role of knowledge variety and intensity for re gional innovation. Small Bus. Econ. 43, 493-509.

Trajtenberg, M., Henderson, R., Jaffe, A., 1997. University versus corporate patents: a window on the basicness of invention. Econ. Innov. New Technol. 5 (1), 19-50.

Tria, F., Loreto, V., Servedio, V.D.P., Strogatz, S.H., 2014. The dynamics of correlated novelties. Sci. Rep. 4 (5890), 1-8.

Van de Vrande, V., 2013. Balancing your technology-sourcing portfolio: how sourcing mode diversity enhances innovative performance. Strateg. Manage. J. 34 (5), 610-621.

Zahra, S.A., George, G., 2002. Absorptive capacity: a review, reconceptualization, and extension. Acad. Manage. Rev. 27 (2), 185-203.

Zhou, K.Z., Li, C.B., 2012. How knowledge affects radical innovation: knowledge base, market knowledge acquisition, and internal knowledge sharing. Strateg. Manage. J. 33 (9), 1090-1102. 